\title{
1 Factors influencing taper failure of modular revision hip
}

2 stems

3 Krull A. *, Morlock M.M.*, Bishop N.E. **

$4 \quad *$ TUHH - Hamburg University of Technology

5 Institute of Biomechanics

6 Denickestrasse 15

721073 Hamburg

8 Germany

$9 \quad * *$ HAW Hamburg University of Applied Science

10 Fakultät Life Science

11 Department Medizintechnik

12 Ulmenliet 20

1321033 Hamburg

14 Germany

Corresponding author:

Annika Krull

annika.krull@tuhh.de

Main text: 4438 words

\section{Abstract}

Stem modularity of revision hip implant systems offers the advantage of the restoration of individual patient geometry but introduces additional interfaces, which are subjected to repetitive bending loading and have a propensity for fretting corrosion. The male stem taper is the weakest part of the modular junction due to its reduced cross section compared to the outside diameter of the stem. Taper fractures can be the consequence of overloading in combination with corrosion. The purpose of this study was to assess the influence of implant design factors, patient factors, and surgical factors on the risk of taper failure of the modular junction of revision stems. 
An analytical bending model was used to estimate the strength of the taper connection for pristine, fatigued and corroded conditions. Additionally, a finite element contact model of the taper connection was developed to assess the relative motion and potential for surface damage at the taper interface under physiological loading for varying assembly and design parameters.

Increasing the male taper diameter was shown to be the most effective means for increasing taper strength but would require a concurrent increase in the outer implant diameter to limit a greater risk of total surface damage for a thinner female taper wall. Increasing the assembly force decreases the total surface damage but not local magnitudes, which are probably responsible for crack initiation. It is suggested that in unfavourable loading conditions a monobloc implant system will reduce the risk of failure.

\section{Keywords}

Hip revision, taper junction, fracture, corrosion, fatigue, strength, titanium, finite element model, surface damage

\section{Highlights}

- Simple stress analysis demonstrates the limited mechanical safety factor at the stem taper junction of modular hip revision systems, indicating that patient loading due to activity and/or weight should be limited.

- Increasing the taper junction diameter increases strength - but contact analysis demonstrated an increase in the risk of total surface damage unless the outer diameter is also increased.

- Contact analysis demonstrated that increasing the assembly force decreases the total surface damage but local magnitudes can still be critical.

\section{Introduction}

The numbers of revision of both primary and revision hip implantations are steadily increasing [1]. Revision rates for first revision at 10 years in national arthroplasty registries between $3 \%$ and $20 \%$ are reported [2-10]. Revision rates of primary implantations in the same registries are much lower (between $2 \%$ and $4 \%$ if metal-on-metal bearing articulation are omitted) $[6,64]$. Revision implantation is more challenging than primary procedures as bone stock has often been lost due to stress shielding and the operative removal of the 
primary implant and the cement mantle, mostly in the proximal region. In anticipation of further revision procedures revision stems are typically uncemented, and are therefore made of titanium alloys which are compatible with bone ingrowth. They are anchored by press-fit in the distal femur. This necessitates a femoral stem that is longer for a revision implant than for a primary stem [11]. Modularity has found widespread application in revision femoral stems as it allows for intra-operative adaptation to the conditions of the femoral bone. Modular systems also require less inventory than monobloc (non-modular) systems. Modular systems incorporate a taper junction between prosthesis neck component and stem, generally located in the proximal third of the implant, allowing the distal stem to be implanted and the proximal neck component to be fitted to the anatomy and assembled subsequently.

Failure of modular connections has been reported to occur by dislocation, corrosion and fracture [12-18]. Failure by fracture of a revision stem is reported at rates of $0.9 \%$ to $3.6 \%$ [4]. Fracture is induced mechanically by fretting, involving the repetitive mechanical disruption of the protective oxide surface layer of the bulk metal due to oscillating relative motion between two surfaces in contact. By definition the amplitude is smaller than the width of nominal contact area. The resulting damage can occur due to wear, fatigue or corrosion. The process of passive oxide film removal due to fretting, followed by corrosion, is called "fretting corrosion". Modular junctions in revision stems are subject to high bending moments, due to their offset (lever arm) from the joint force vector, especially in situations without proximal bone support. Patient anatomy and body weight also influence bending loading of the taper $[14,16,18-20]$. The diameter of the intramedullary canal limits the maximum diameter of the stem that can be implanted. Increased loading cannot always be compensated by implant dimensions, leading to limited flexural strength [14,17-19,23,24]. This also applies to the taper dimensions, which are limited by the outside diameter of the implant. Failure has also been documented for the stem-head taper junction, particularly in association with the re-introduction of large diameter metal-on-metal joints, which can generate increased joint friction moments [13-18].

Failure of revision stems is generally due to fatigue fracture $[24,25]$. Fracture of an implant occurs when stresses exceed the material strength. Pristine components have the greatest strength, which decreases with fatigue loading and corrosion. Higher assembly forces have 
the potential to reduce fretting by increasing the press-fit [26-28]. A parametric analysis of the major factors responsible for prosthesis failure is not available.

The purpose of this study was therefore to investigate the influence of joint loading, stem taper geometry, material characteristics and assembly force on potential taper failure of modular revision hip stems.

\section{Materials and Methods}

Stress magnitudes were assessed analytically for different realistic implant geometries and patient loading scenarios, and related to the strength of the material in various states of degradation by fatigue and corrosion. The influence of the modular taper design and assembly force on degradation of the material by surface damage were also analysed, using finite element (FE) analysis. For validation of the analytical and numerical models, experimental determination of the fracture load, seating depth and gap opening at the taper connection under different assembly loads were performed.

A clinically successful modular THA revision prosthesis system (MRP, Peter Brehm GmbH, Germany) was used as basis for the analysis [22]. The femoral implant of the MRP consists of a distal stem and a proximal neck piece (Figure 1A). For this study a neck piece with a CCD angle of $130^{\circ}$ was used (Figure $1 \mathrm{C}$ ). Both components are made from Ti6Al4V alloy (Ti) and have an outside diameter of $20 \mathrm{~mm}$. The components are joined by a taper connection with a diameter of $\sim 12 \mathrm{~mm}$ for the male taper, a taper angle of $1.4^{\circ}$ (from the mid-axis) and a contact length between male and female components of $19.5 \mathrm{~mm}$ when assembled. The lateralised proximal neck piece in combination with an L4 prosthesis head $(+16 \mathrm{~mm})$ produces a horizontal offset of $53 \mathrm{~mm}$. This was investigated as a worst-case loading scenario of the taper connection ("high offset"; Figure 1C), since this results in the highest bending moment possible at the modular junction. This combination is not approved by the manufacturer but is used clinically. For comparison a "short" $(-5 \mathrm{~mm})$ head with a standard neck piece producing a horizontal offset of $30 \mathrm{~mm}$ was also investigated ("low offset"; Figure 1C).

\section{Analytical}

A simple beam bending model was used to calculate the maximum bending stresses $\sigma_{\max }$ for the outside surface of the male taper of the distal stem, according to joint loading and implant geometry (Figure 1B). The joint load was assumed to act through the centre of the 
125 prosthesis head, in the plane of the implant and at an angle $\theta$ to the vertical implant axis.

126 The bending moment $M$ acting around the centre of the male taper of the distal stem, at the

127 level of the open end of the proximal neck piece, was calculated from the joint force vector and its distance $\Delta$ from this point (Figure 1D). The radius $R$ of the male taper of the distal stem at this point was varied. Peak joint forces $F$ measured in vivo during walking and stumbling for a light $(60 \mathrm{~kg})$ and a heavy patient $(120 \mathrm{~kg})$ [29] were applied. Calculated stresses were compared with the strength of pristine Ti6Al4V ( $\left.\widehat{\sigma}_{\text {pristine }}=1000 \mathrm{MPa}\right)$ [53], a fatigued material at $10^{7}$ cycles $\left(\widehat{\sigma}_{\text {fatigue }}=750 \mathrm{MPa}\right)$ [30] and a severely corroded material $\left(\hat{\sigma}_{\text {corrosion }}=200 \mathrm{MPa}\right)[30]$.

The analysis assumes linear bending theory. Stresses due to the axial and shear force components are neglected as they are relatively small [63]. It was assumed that there was no bony support of the proximal neck piece.

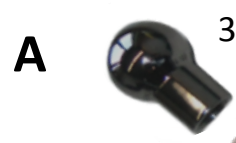

3

2

1

B $\quad \sigma_{\max }=\frac{M \cdot y_{\max }}{I}=\frac{(F \cdot \Delta) \cdot R}{\left(\pi \cdot R^{4} / 4\right)}=\frac{4 \cdot F \cdot\left(\Delta_{x} \cdot \cos (\theta)-\Delta_{y} \cdot \sin (\theta)\right)}{\pi \cdot R^{3}}$
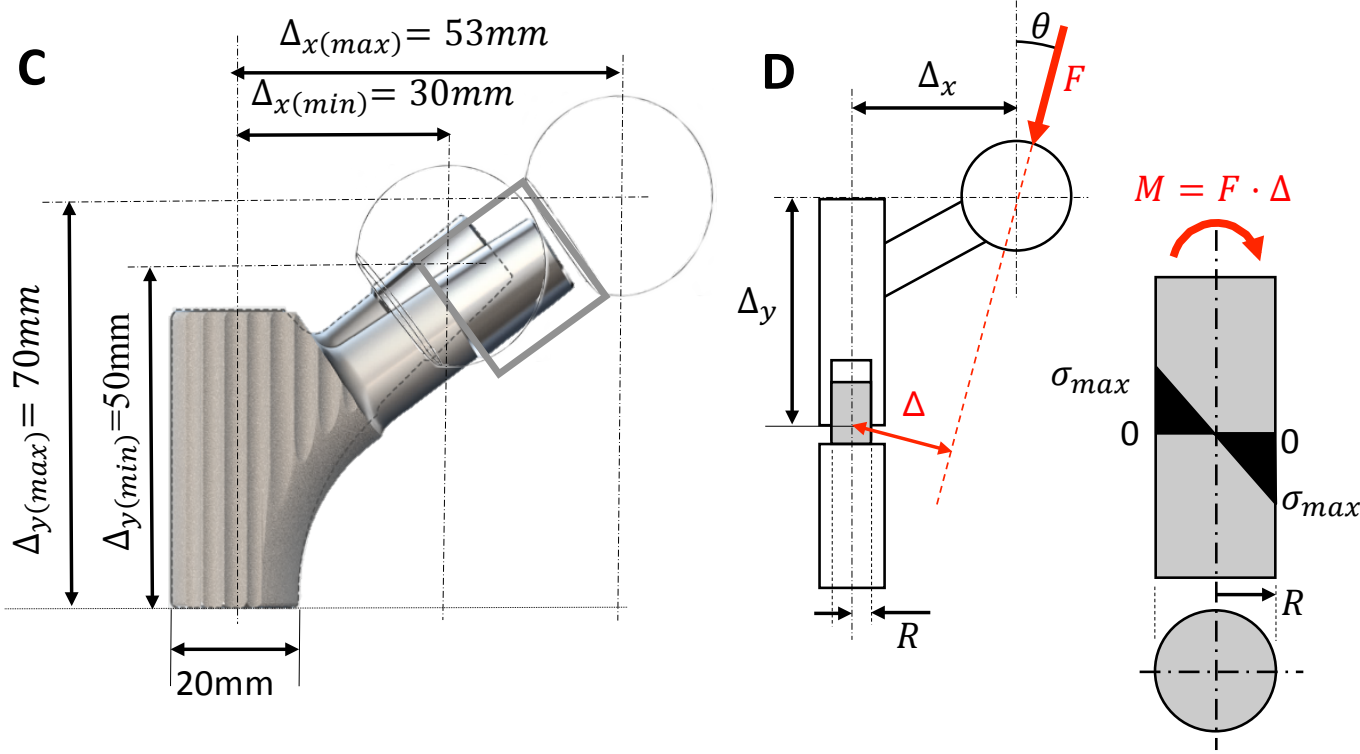

Figure 1: A: The femoral component consisting of distal stem (1), proximal neck piece (2), prosthesis head (3); 
B: Equation for the calculation of maximum bending stress $\sigma_{\max }$ at the male taper of the distal stem. $M$ is the applied bending moment, $y_{\max }$ the maximum distance from the neutral plane, $I$ is the second moment of area around the bending axis, $F$ is the joint force, $\Delta$ is the perpendicular distance from the force vector to the taper, $\theta$ is the angle of the joint force to the vertical implant axis and $R$ is the radius of the male taper at the level of the open end of the proximal taper (circular cross section);

C: "High" and "low" offset geometries investigated;

D: Representation of the male taper stressed in bending due to the joint force and its offset from the taper. The moment $M$ acting around the taper connection is derived from the joint force $\mathrm{F}$ acting at an offset $\Delta$ from the taper.

\section{Numerical}

Fretting damage can occur when small relative motions between two interface surfaces in contact occur $[21,26]$, which abrade the protective oxide layers. In a fluid environment, metal ions can leave the bare metal surface, which is known as fretting corrosion [31]. In titanium alloys this leads to a roughened surface that causes stress concentrations as sites of crack nucleation [32].

A finite element model of the stem taper junction was generated (Abaqus 6.14, Dassault Systèmes, France) based on CAD data of the MRP-System (Figure 2A). Contact analysis of the taper interface was implemented to investigate mechanical and design factors potentially influencing fretting damage. Linearly elastic, homogeneous, isotropic material properties for the titanium alloy Ti6Al4V Ti were used $(E=113.8 \mathrm{GPa} ; \mathrm{v}=0.34)$. The friction coefficient for contact of the alloy surfaces was set to $\mu=0.35[33,34]$.

A mesh convergence analysis resulted in a suitable element size of $0.8 \mathrm{~mm}$ on the contact surface of the taper junction (proximal neck piece and distal stem), resulting in 105,837 elements for the distal stem and changes of less than $2 \%$ in gap opening and seating depth between mesh refinements. Relative shear interface motion and contact pressure were sampled at each node of the surface of the male taper. Assembly forces were varied between $0.5 \mathrm{kN}$ and $40.0 \mathrm{kN}$, representing very low intraoperative values and very high laboratory values, respectively. Physiological joint loading for a walking cycle of a $75 \mathrm{~kg}$ patient was applied, according to in-vivo measurements in joint replacement patients [29]. 
171 Relative shear interface motion and pressure at each node were multiplied to obtain a factor

172 representing relative surface damage for ten equally spaced time intervals of the loading cycle (based on Archard's law [35,36]). Total surface damage was determined by summing over all nodes and all time intervals.

The influence of prosthesis design was investigated by the variation of the male taper diameter between $8 \mathrm{~mm}$ and $16 \mathrm{~mm}$, with the outside diameter of the implant maintained at $20.0 \mathrm{~mm}$, the length of contact at $19.5 \mathrm{~mm}$ and the taper angle at $1.4^{\circ}$ (Figure 2B). For this parametric analysis an assembly force of $11.0 \mathrm{kN}$ was applied, followed by the peak joint force in a gait cycle [29].

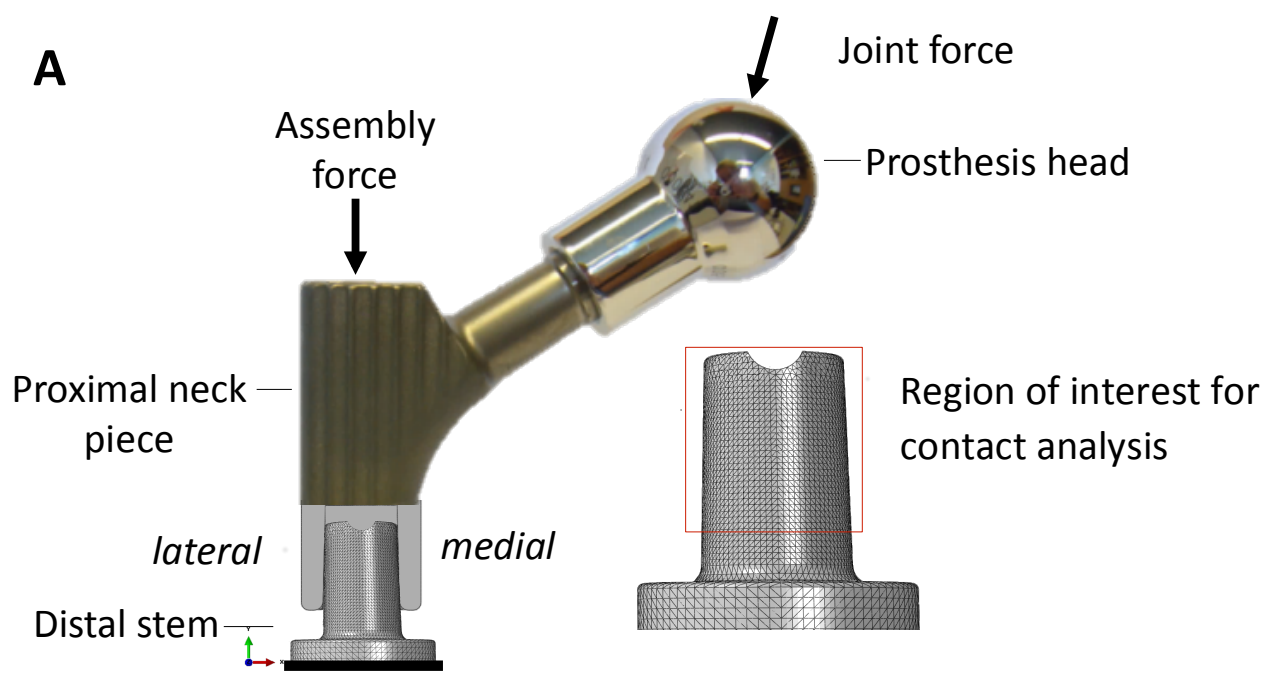

B Male taper diameter variation of the distal stem:

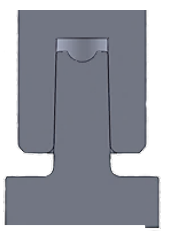

$8 \mathrm{~mm}$

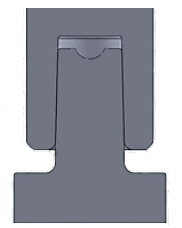

$10 \mathrm{~mm}$

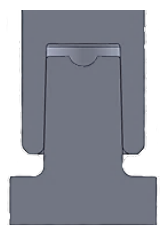

$12 \mathrm{~mm}$

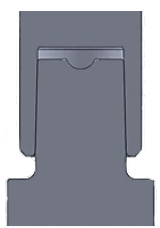

$14 \mathrm{~mm}$

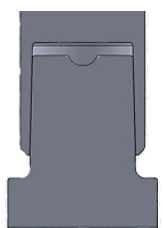

$16 \mathrm{~mm}$

Figure 2: A: The numerical model (grey) with loading applied to represent the applied forces shown;

B: Variation of the diameter of the male stem taper between $8 \mathrm{~mm}$ and $16 \mathrm{~mm}$. $12 \mathrm{~mm}$ represents the clinically available implant.

\section{Validation}

For experimental validation of the analytical bending stress model, the fracture load of the modular implant was determined and compared with the analytical prediction. The proximal 
neck piece was assembled under $9.0 \mathrm{kN}$ on a replica of the distal stem piece (produced by the implant manufacturer) using a materials testing machine (Zwick Z010, Zwick GmbH \& Co.KG, Germany; in accordance with ISO 7206-10; $0.04 \mathrm{~mm} / \mathrm{s})$. The prosthesis head was then loaded vertically until fracture of the taper $(n=3)$. The peak force was recorded.

For experimental validation of the FE model, the opening of the gap at the taper interface was measured in the radial direction at the lateral side using a chromatic confocal sensor (DT IFS 2403-1.5, Micro-Epsilon Messtechnik GmbH, Germany; measurement range: $1.5 \mathrm{~mm}$, resolution $60 \mathrm{~nm}$ ) mounted on the outside surface on an aluminium clamp (Figure 3A). The change in distance to the male taper surface was measured through a $1.5 \mathrm{~mm}$ diameter hole drilled through the proximal neck piece at the lower edge of the lateral side. Measurements were repeated three times.

The two prosthesis components were assembled quasi-statically at $0.04 \mathrm{~mm} / \mathrm{s}$ (ISO 7206-10) with forces of $0.5,5.0$ and $9.0 \mathrm{kN}$, along the taper axis using a materials testing machine (Zwick Z010, Zwick GmbH \& Co.KG, Germany). After assembly, a joint force of 0.5, 1.5 or $2.5 \mathrm{kN}$ was applied under quasistatic displacement $(0.04 \mathrm{~mm} / \mathrm{s})$ to the prosthetic head with a horizontal offset of $53 \mathrm{~mm}$ along an axis parallel to the stem taper axis $(0.04 \mathrm{~mm} / \mathrm{s})$. The 2.5 $\mathrm{kN}$ joint force reflects magnitudes measured for gait [29]. The seating depth (Figure 3B) after assembly and the gap opening (Figure $3 \mathrm{C}$ ) at the taper junction between the proximal neck piece and the distal stem at the lateral side of the female taper opening were measured.

The seating depth was derived from the difference in axial position of the proximal neck piece on the distal stem component measured before and after assembly using a coordinate measurement machine (Mitutoyo BHN 305; Mitutoyo Deutschland GmbH, Germany; accuracy $2 \mu \mathrm{m})$. One measurement was performed for each assembly force $(n=3)$. No joint force was applied during these tests. 


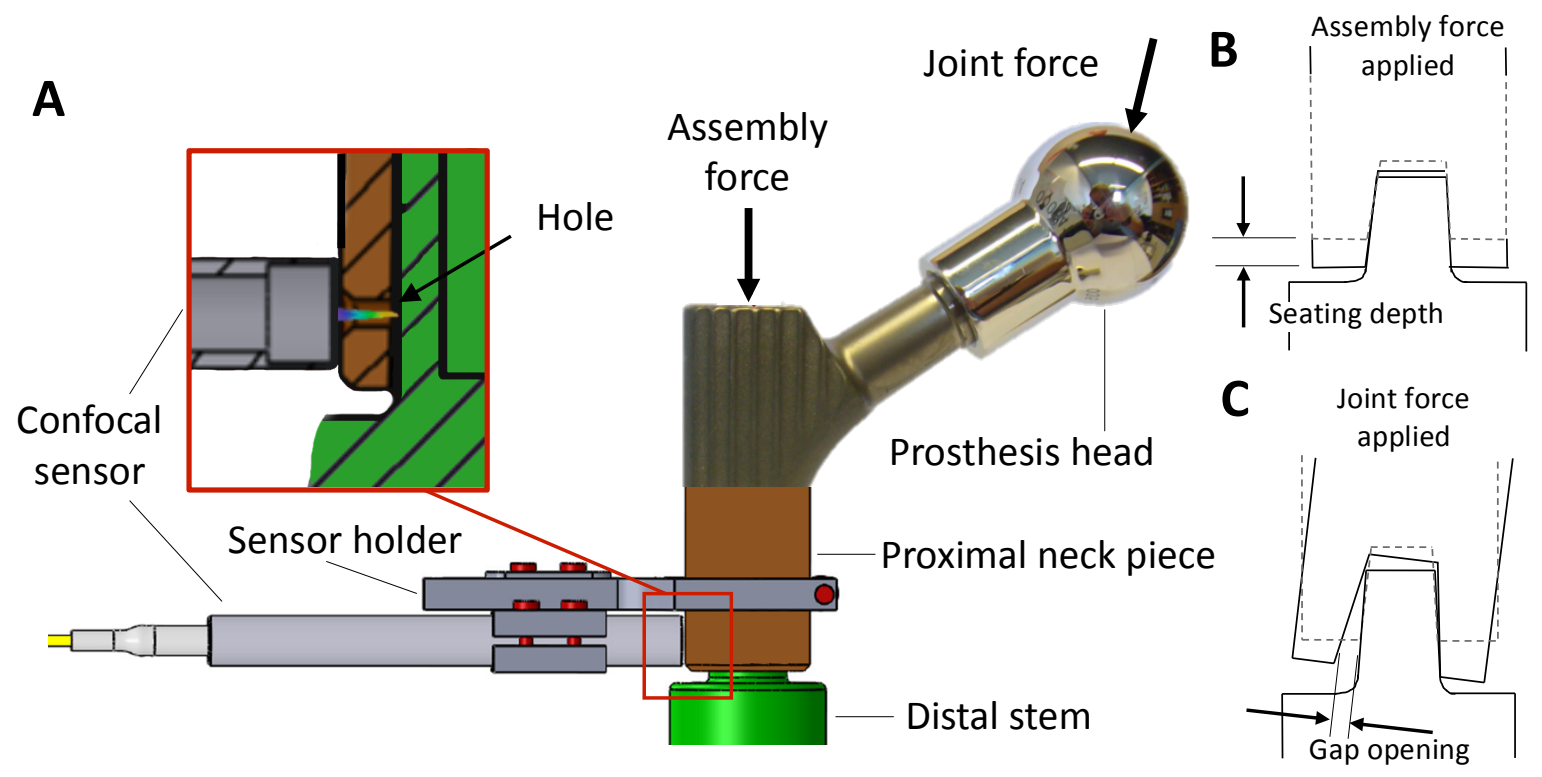

Figure 3: A: Gap opening at the taper junction was measured through a small hole in the proximal neck piece using a confocal sensor mounted on the proximal neck piece;

B: Illustration of the seating depth between the proximal neck piece and the distal stem due to an applied assembly force;

C: Illustration of the gap opening between the proximal neck piece and the distal stem due to joint force.

Results

\section{Analytical}

The bending model predicted taper failure for the standard taper diameter $(12 \mathrm{~mm})$ for the pristine material condition only under high offset in a heavy patient under a stumbling load (Figure 4). The same implant configuration failed for a light patient stumbling or a heavy patient walking for the fatigued material after $10^{7}$ loading cycles. Increasing the male taper diameter to $16 \mathrm{~mm}$ prevented failure of the pristine or fatigued components for any patient, geometry or loading (Figure 4).

The corroded material led to failure for almost any condition for the standard diameter taper. Increasing the taper diameter to $20 \mathrm{~mm}$, which would correspond to a monobloc implant of this dimension, protected against failure in almost all conditions, excepting a heavy patient stumbling with a high offset implant. 


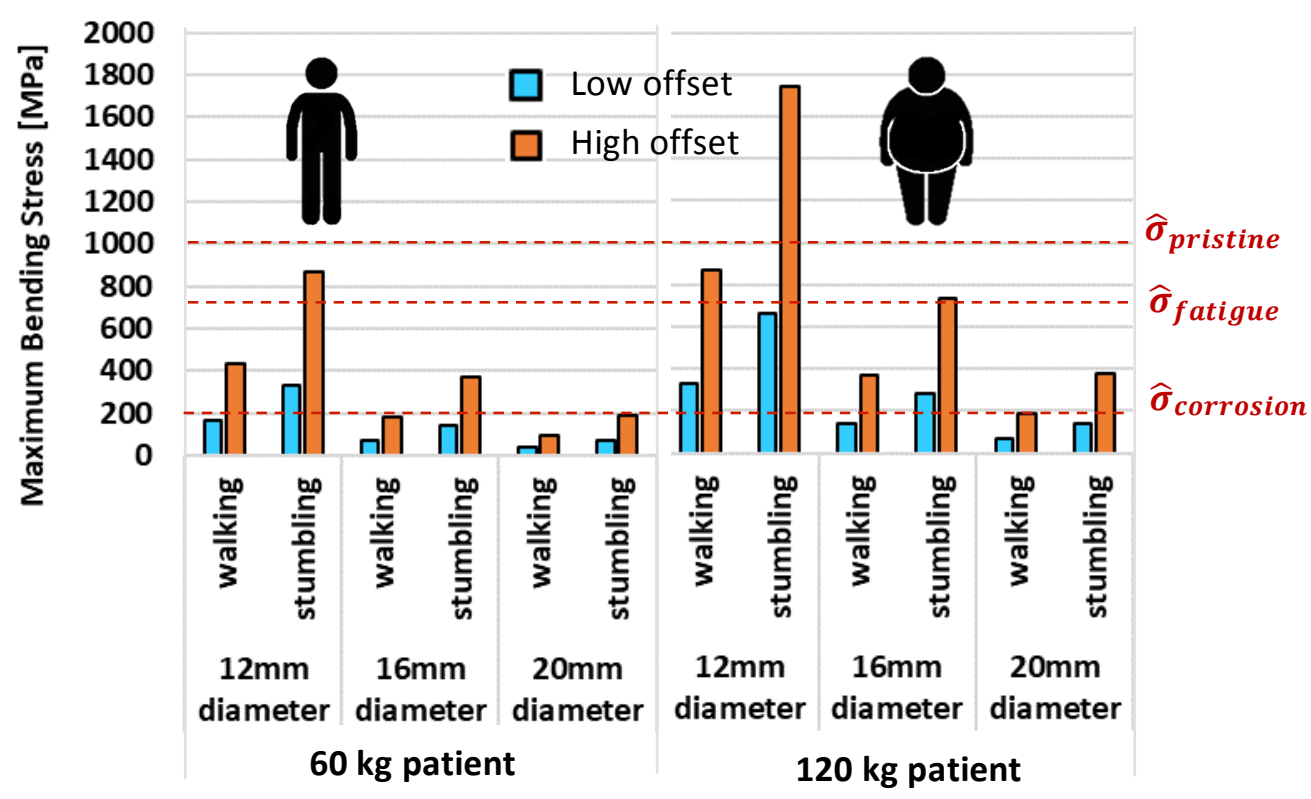

Figure 4: Peak bending stresses for the male taper of the distal stem for low $(60 \mathrm{~kg})$ and high patient mass $(120 \mathrm{~kg})$, low $(30 \mathrm{~mm})$ and high offset $(53 \mathrm{~mm})$ and varying diameters of the male stem taper $(12 \mathrm{~mm}, 16 \mathrm{~mm}$ and $20 \mathrm{~mm})$. Failure stresses of the different material conditions (pristine, fatigue and corrosion) are indicated.

Finite element model

An increase in contact pressure and contact area as well as a decrease in relative motion under joint loading were found for increasing assembly force (Figure 5A, Table 1). Gap opening was observed in the proximal-lateral and distal-medial regions and was reduced with increasing assembly force (Figure 5A, Table 1). The same peak magnitude of the total surface damage was observed for all assembly forces, despite decreasing relative motion for higher assembly forces, due to the increased contact pressure (Table 1). Peak total surface damage was observed in distal-lateral and proximal-medial regions for low assembly forces $(0.5 \mathrm{kN})$, over the whole of the lateral and medial surfaces for increased assembly force $(11.0 \mathrm{kN})$ and in the distal regions of the lateral and medial surfaces for very high assembly loads $(40.0 \mathrm{kN})$ (Figure $5 \mathrm{~A})$. The greatest total surface damage was observed for the periods of the joint loading cycle with the highest rates of loading and unloading (heel strike and toe off; Figure 5B). The total surface damage integrated over the taper surface for a whole gait cycle decreased with increasing assembly force: $4.33 \mathrm{MPa} \cdot \mathrm{mm}, 1.73 \mathrm{MPa} \cdot \mathrm{mm}$ and $0.14 \mathrm{MPa} \cdot \mathrm{mm}$ for $0.5 \mathrm{kN}, 11.0 \mathrm{kN}$ and $40.0 \mathrm{kN}$, respectively (Figure 5B, Table 1). 


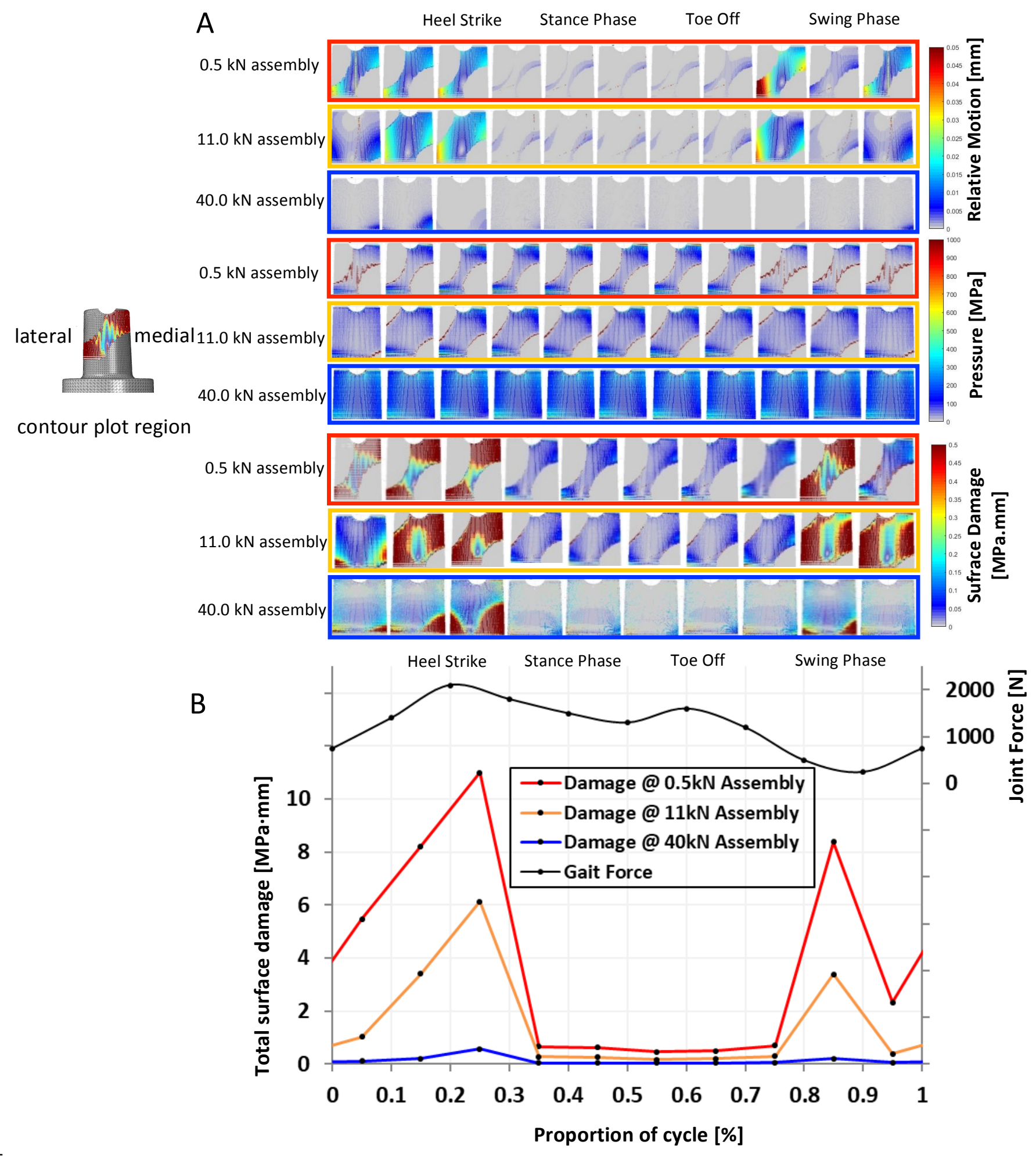

Figure 5 : A: Contour plots of the relative motion, pressure and relative surface damage for each tenth of the gait cycle for three assembly forces (the colours of the frames reflects the different assembly forces and corresponds to the colours in part B of this figure);

B: Total surface damage for the entire surface for each tenth of the gait cycle, starting and ending with the swing phase of the leg. 
Table 1: Maximum relative motion [mm], contact pressure [MPa], gap opening [mm] during a gait cycle, and total surface damage [MPa.mm] integrated over the whole gait cycle for the different assembly forces $[\mathrm{kN}]$ from the FE analysis.

\begin{tabular}{c|cccc}
$\begin{array}{c}\text { Assembly } \\
\text { force } \\
{[\mathrm{kN}]}\end{array}$ & $\begin{array}{c}\text { Relative } \\
\text { motion } \\
{[\mathrm{mm}]}\end{array}$ & $\begin{array}{c}\text { Contact } \\
\text { pressure } \\
{[\mathrm{MPa}]}\end{array}$ & $\begin{array}{c}\text { Gap opening } \\
{[\mathrm{mm}]}\end{array}$ & $\begin{array}{c}\text { Total surface damage integrated } \\
\text { over the whole gait cycle } \\
{[\mathrm{MPa} \cdot \mathrm{mm}]}\end{array}$ \\
\hline 0.5 & 0.01200 & 92.24 & 0.047 & 4.33 \\
11.0 & 0.00540 & 128.93 & 0.026 & 1.73 \\
40.0 & 0.00072 & 205.73 & 0.003 & 0.14
\end{tabular}

262 The total surface damage of the different taper diameters (assembly force $11.0 \mathrm{kN}$ and peak force of physiological gait loading) showed the smallest magnitude for condition " $c$ " (Figure 6), which is the design used clinically.

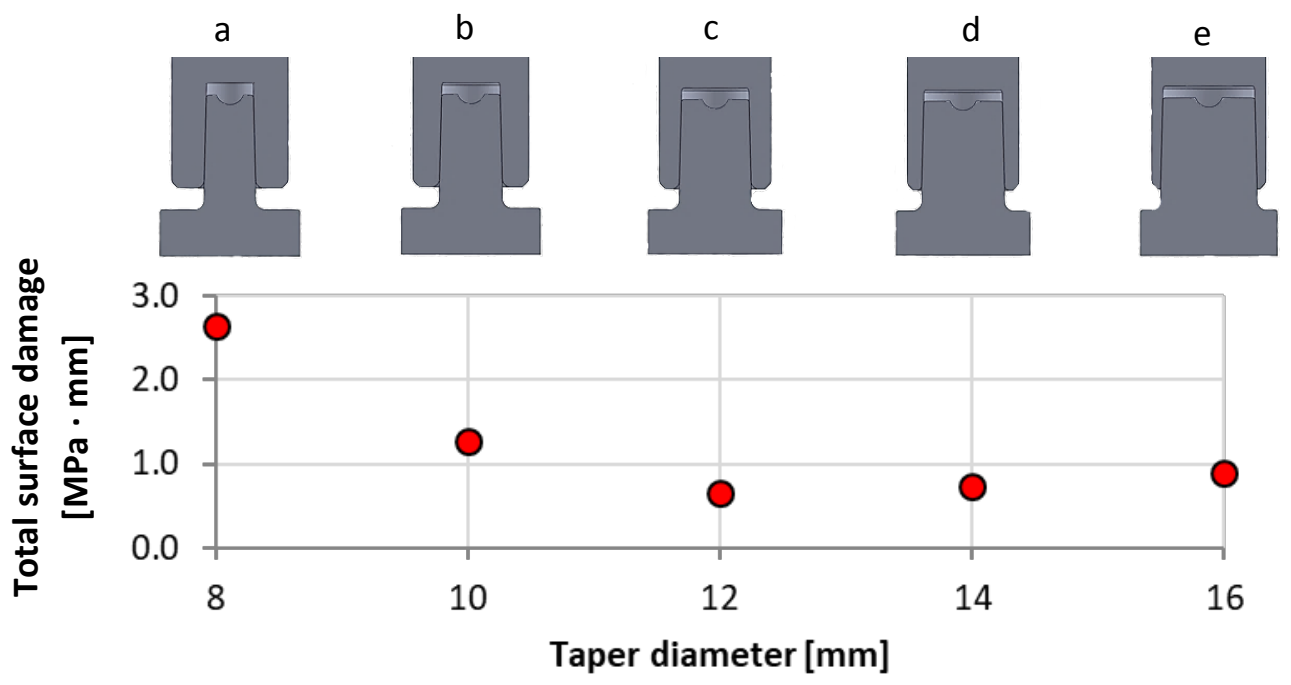

Figure 6: Total surface damage of the taper interface of the distal stem for varied taper diameter ( $8 \mathrm{~mm}-16 \mathrm{~mm}$ ) with a constant outside diameter of $20 \mathrm{~mm}$, an assembly force of $11.0 \mathrm{kN}$ for the peak force of physiological gait loading. Design c is the clinically available implant design.

\section{Validation}

Experimental failure testing (Figure 7A) resulted in a mean fracture load of $5.65 \pm 0.61 \mathrm{kN}$, with initiation of the crack observed at the lateral side of the distal stem taper (Figure 7B),

273 similar to the location of the highest values of bending stress of the FE-calculation and likewise comparable to in-vivo fracture images of the taper junction of modular revision 
prosthesis (Figure 7C) and likewise comparable to in-vivo fracture images of the taper junction of modular revision prosthesis (Figure $7 \mathrm{C}$ ). The failure force predicted for the analytical bending model was $6.06 \mathrm{kN}$, which is an overestimation of less than $8 \%$.

\section{A}

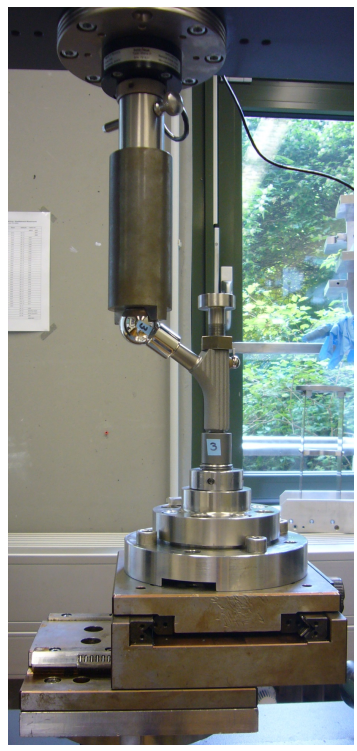

B
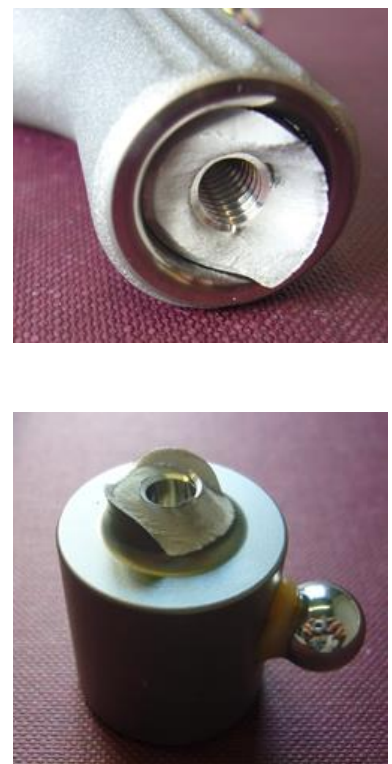

C

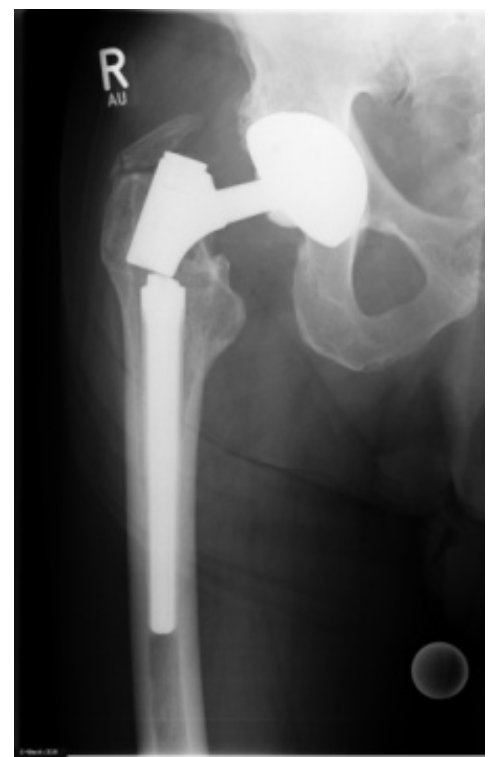

Figure 7: A: Experimental setup for the determination of the fracture load of the distal stem taper;

B: Fracture surfaces of the male taper;

C: X-ray of a fractured taper junction of a modular revision hip system [65].

Lateral gap opening increased with applied joint force and decreased with assembly force similarly for the numerical model and the experiment (Figure 8). A maximum gap opening of $86.1 \pm 11.1 \mu \mathrm{m}$ was measured for $0.5 \mathrm{kN}$ assembly force and a joint force of $2.5 \mathrm{kN}$. The mean absolute error for the gap opening was highest for the lowest assembly force with the highest joint force (21\%). For all other combinations the error was less than $7 \%$.

The seating depth of the taper increased with increasing assembly force similarly for the model calculations and the experimental measurements (Figure 8). Seating depths of $231 \pm 20 \mu \mathrm{m}$ and $754 \pm 55 \mu \mathrm{m}$ were measured for assembly forces of $0.5 \mathrm{kN}$ and $9.0 \mathrm{kN}$, respectively. The mean difference between calculated and measured seating depth magnitudes was between $3 \%$ and $8 \%$. 


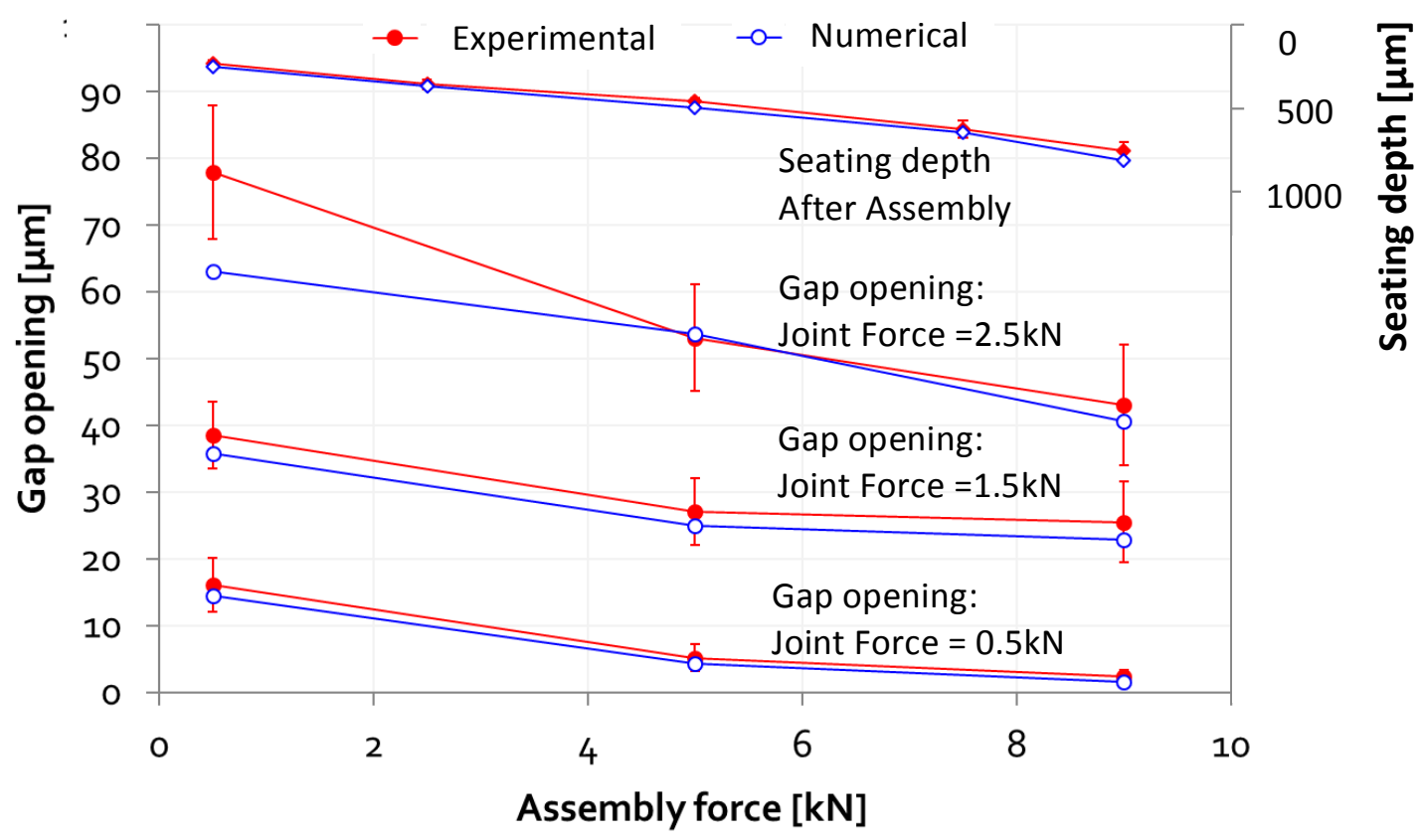

Figure 8: Comparison of experimental and numerical results (FE-model) for gap opening and seating depth between the proximal neck piece and the distal stem for varying assembly forces and joint force.

\section{Discussion}

In this study various implant design factors, as well as surgeon and patient factors were investigated for their potential to cause failure of modular stem taper connections of femoral revision implants.

Design constraints for a revision stem

Revision stems are designed to achieve stability in the femoral diaphysis to bypass regions of proximal bone loss. Their outside diameter is limited by the cross section of the medullary canal. The head offset and angle of the neck piece should be matched to the patient's anatomy to achieve a satisfactory functional outcome. Titanium alloy is used for uncemented implants due to its biocompatibility and strength. The bending model demonstrated that a solid monobloc stem can have the strength to sustain most loading situations in most patients, without proximal bone support. The diameter of the male taper must be smaller than the outside diameter of a monobloc design. A modular stem is therefore weaker, but allows stable diaphyseal fixation and appropriate geometrical reconstruction to be achieved independently in the operating theatre [37]. 
313 The results of the analytical model indicate that problems with modular implants can occur for higher loading of heavy patients, a phenomenon for which is anecdotal clinical evidence $[19,38,39]$. Larger patients are associated with higher joint loading as well as higher neck offsets. Of all the factors investigated in this study, increasing the taper diameter was shown to provide the greatest advantage, since implant strength increases with the cube of the diameter. This might be a solution for patients with a medullary canal that is sufficiently large to accommodate an increased stem diameter.

The male taper diameter could also be increased for a given canal diameter by decreasing the wall thickness of the (outer) female taper. The numerical simulation showed that this would increase the relative motion and surface damage at the interface. Interestingly, the minimum relative motion and surface damage were observed for the wall thickness of current clinical designs. An alternative solution would be the use a monobloc implant (no taper connection), for which the outside diameter determines the bending strength. This solution was shown to be sufficiently strong for most patients undertaking normal activities.

The maximum bending stress generated is proportional to the lever arm of the joint force. The joint force angle remains rather constant in the femoral (or stem) coordinate system during a gait cycle and for other activities, suggesting that the vulnerable taper connection could be positioned in the area where it intersects with the joint force vector, thus minimizing the lever arm and the risk of failure. In current designs the modular taper lies above this position. For the minimum head offset design the position would need to lie $28 \mathrm{~mm}$ lower and for the maximum head offset $74 \mathrm{~mm}$ lower than current designs. However, these geometries would be impractical as they would interfere with the diaphyseal anchorage of the stem.

Other factors influencing the mechanical failure of modular revision stems are related to the patient and to the surgeon. If the patient is heavy and/or requires a high offset neck but has a small endosteal diameter, and if a larger diameter taper is not available, the restriction of activities or even weight loss would be indicated [54-56]. It is doubtful whether such advice to patients would be practical.

One of the surgeon factors investigated in the current study was the assembly force applied over the taper connection. This does not affect the immediate post-operative strength of the stem but rather the loss of taper strength with time, by accelerating and accentuating the 
fatigue process of the material. Fatigue is inevitable and will reduce the strength of the material by $10 \%$ at just $10^{5}$ cycles (less than one year of standard post-operative activity) and approaches a limit of $20 \%$ reduction at $10^{7}$ cycles ( $\sim$ a few years, depending on age and activity) [40-42]. The influence of corrosion on implant failure is currently undergoing extensive research for the head-stem junction [43-46]. Corrosion of titanium-titanium modular connections has led to clinical failure by accentuated fatigue [47] and by a loss of strength due to a transition of the bulk metal to the crumbly oxide [48]. In the current study this effect was investigated for the stem taper, which is subjected to a larger bending moment than the head-stem taper. The magnitudes of motion simulated at this interface support the suggestion that fretting corrosion is likely to occur at this interface. Assuming that the combination of relative shear motion and contact pressure causes surface damage, maximum surface damage was observed during heel strike and toe off, where the rates of change of loading are maximum (Figure 5B). The integration of relative surface damage over a whole gait cycle was an order of magnitude higher for the low assembly force $(0.5 \mathrm{kN})$ than for the manufacturer's suggested magnitude $(11.0 \mathrm{kN})$. Application of a very large assembly force $(40.0 \mathrm{kN})$ reduced total surface damage by a further $8 \%$ but high local magnitudes were still observed. Therefore, increasing the assembly force may not completely eliminate local fretting.

Corrosion can only occur in a fluid environment [49-52]. The gap opening measured in the current study could allow joint fluid to enter the interface. On the other hand, runaway crevice corrosion occurs in relatively stagnant fluid conditions, in which the fluid becomes increasingly acidic and corrosive [51]. Fluid can permeate the interface without any loading, regardless of the assembly force, due to the surface roughness (unpublished data), so that gap opening may have little further impact.

\section{Limitations}

The analytical and numerical models presented were shown to be valid representations of similar experimental models. However, various factors were neglected that may influence clinical implant performance. Neglecting proximal bone support represents worst case taper loading, but may represent clinical reality [57-60]. Stumbling also represents worst case loading. It is unknown how frequently this occurs $[61,62]$. 
374 The strength of the pristine and fatigued material without corrosion is well defined but

375 further loss of strength due to corrosion is difficult to measure. Corrosion in titanium

376 modular connections between head and stem has been observed to lead to material loss as the titanium is converted to a crumbly oxide [48]. This has not yet been reported for revision stems, but their fatigue is apparently accentuated by surface corrosion, which roughens the surface and facilitates crack initiation [13,45-47].

380 A single implant design was used as a template in the current study. Many of the implants available have a similar geometry, due to their constraint by anatomical geometry. The implant used would therefore seem to be representative of other implants.

\section{Conclusions}

This study addressed revision implantation without any proximal bone support around the neck piece. For this situation the mechanical limits of modular revision implants can be exceeded, particularly after some time in the body, and in larger patients. Since a voluntary reduction of implant loading by the restriction of activities or by weight loss is difficult to ensure, a larger diameter implant or a monobloc design should be considered in order to increase implant strength. This would require a greater inventory in the hospital and might be restricted to specialized centres. Increasing the assembly force was shown to increase the contact pressure and decrease the relative interface motion. However, an increased assembly force does not eliminate local wear or fretting entirely, demonstrating that any taper junction can carry the risk of corrosion. 
395 Funding:

396 Ethical approval:

397 Annika Krull, has declared no conflict of interest. Michael M. Morlock, reports personal fees 398 from DePuy Synthes, Zimmer, Ceramtec, Smith \& Nephew, Aesculap and Corin; grants from 399 DePuy Synthes and Ceramtec outside the work. Nicholas E. Bishop, reports personal fees 400 from DePuy Synthes outside the work.

401 Acknowledgments:

402 The authors would like to thank Peter Brehm GmbH (Weissendorf, Germany) for providing 403 materials.

404 Author's contribution:

405 We confirm that the article is original, that all authors were involved in the study design, 406 data collection, data analysis and writing; the paper has not been submitted to any other 407 journal. 


\section{References}

[1] Kurtz S, Mowat F, Ong K, Chan N, Lau E, Halpern M. Prevalence of primary and revision total hip and knee arthroplasty in the United States from 1990 through 2002. The Journal of bone and joint surgery. American volume 2005;87(7):1487-97, doi:10.2106/JBJS.D.02441.

[2] Berry DJ. American Joint Replacement Registry 2016.

[3] Canadian Institute for Health Information / Institut canadien d'information sur la santé. Canadian Joint Replacement Registry Annual Report 2015.

[4] Australian Orthopaedic Association. National joint replacement registry. Revision hip and knee arthroplasty. Supplementary report 2016.

[5] Graves S. National Joint Replacement Registry, Hip Knee \& Shoulder Arthroplasty, Annual Report 2016.

[6] Green M, Howard PW, Porter M, Price A, Wilkinson JM, Wishart N. National Joint Registry for England, Wales, Northern Ireland and the Isle of Man, 13th Annual Report 2016.

[7] Grumberg A, Jansson V., Liebs T, Melsheimer O, Steinbruck A. Endoprothesenregister Deutschland (EPRD) 2015.

[8] Overgaard S. Dansk Hoftealloplastik Register - National arsrapport 2016.

[9] Röder C, Staub Lucas P. Jahresbericht 2014 Schweizerisches Hüft- und Knieimplantatregister. PrimaryCare (de);15(14). p. 234-235, doi:10.4414/pcd.2015.01082.

[10] Rothwell A. The new zealand joint registry 2016.

[11] Egan KJ, Di Cesare PE. Intraoperative complications of revision hip arthroplasty using a fully porous-coated straight cobalt-chrome femoral stem. The Journal of Arthroplasty 1995;10:S45-S51, doi:10.1016/S0883-5403(05)80230-X.

[12] Bobyn JD, Tanzer M, Krygier JJ, Dujovne AR, Brooks CE. Concerns with modularity in total hip arthroplasty. Clin Orthop Relat Res 1994(298):27-36.

[13] Atwood SA. Corrosion-Induced Fracture of a Double-Modular Hip Prothesis. J Bone Joint Surg Am 2010;92(6), doi:10.2106/JBJS.I.00980.

[14] Efe T, Schmitt J. Analyses of prosthesis stem failures in noncemented modular hip revision prostheses. The Journal of Arthroplasty 2011;26(4):665, doi:10.1016/j.arth.2010.05.020.

[15] Ceretti M, Falez F. Modular titanium alloy neck failure in total hip replacement: Analysis of a relapse case. SICOT-J 2016;2:20, doi:10.1051/sicotj/2016009.

[16] Fink B, Urbansky K, Schuster P. Midterm results with the curved modular tapered, fluted titanium Revitan stem in revision hip replacement. The Bone \& Joint Journal 2014;96-B(7):889-95, doi:10.1302/0301-620X.96B7.33280.

[17] Konan S, Garbuz DS, Masri BA, Duncan CP. Modular tapered titanium stems in revision arthroplasty of the hip: The Risk and Causes of Stem Fracture. The Bone \& Joint Journal 2016;98-B(1 Suppl A):50-53, doi:10.1302/0301-620X.98B1.36442. 
[18] Lakstein D, Eliaz N, Levi O, Backstein D, Kosashvili Y, Safir O, Gross AE. Fracture of cementless femoral stems at the mid-stem junction in modular revision hip arthroplasty systems. The Journal of bone and joint surgery. American volume 2011;93(1):57-65, doi:10.2106/JBJS.I.01589.

[19] Wroblewski BM. The mechanism of fracture of the femoral prosthesis in total hip replacement. International Orthopaedics (SICOT) 1979;3:137-39.

[20] Van Houwelingen, Andrew P, Duncan CP, Masri BA, Greidanus NV, Garbuz DS. High survival of modular tapered stems for proximal femoral bone defects at 5 to 10 years follow up. Clinical Orthopaedics and Related Research 2013;471(2):454-62, doi:10.1007/s11999-012-2552-8.

[21] Cooper HJ, Della Valle CJ, Berger RA, Tetreault M, Paprosky WG, Sporer SM, Jacobs JJ. Corrosion at the Head-Neck Taper as a Cause for Adverse Local Tissue Reactions After Total Hip Arthroplasty. The Journal of Bone and Joint Surgery 2012;94(18):1655-61, doi:10.2106/JBJS.K.01352.

[22] Hoberg $M$, Konrads C, Engelin J, Oschmann D, Holder M, Walch M, Rudert M. Outcome of a modular tapered uncemented titanium femoral stem in revision hip arthroplasty. Int Orthop. 2015(39,9):1709-13, doi: 10.1007/s00264-015-2699-5.

[23] Wright G, Sporer S, Urban R, Jacobs J. Fracture of a modular femoral neck after total hip arthroplasty: A case report. The Journal of bone and joint surgery. American volume 2010;92(6):1518-21, doi:10.2106/JBJS.I.01033.

[24] Norman P, lyengar S, Svensson I, Flivik G. Fatigue fracture in dual modular revision total hip arthroplasty stems: failure analysis and computed tomography diagnostics in two cases. The Journal of Arthroplasty 2014;29(4):850-55, doi:10.1016/j.arth.2013.09.008.

[25] Masri BA, Meek RMD, Duncan CP. Periprosthetic Fractures Evaluation and Treatment. Clinical Orthopaedics and Related Research 2004;420:80-95, doi:10.1097/00003086200403000-00012.

[26] Gilbert JL, Buckley CA, Jacobs JJ. In vivo corrosion of modular hip prosthesis components in mixed and similar metal combinations. The effect of crevice, stress, motion, and alloy coupling. J. Biomed. Mater. Res. 1993;27(12):1533-44, doi:10.1002/jbm.820271210.

[27] Mroczkowski ML, Hertzler JS, Humphrey SM, Johnson T, Blanchard CR. Effect of impact assembly on the fretting corrosion of modular hip tapers. Journal of orthopaedic research official publication of the Orthopaedic Research Society 2006;24(2):271-79, doi:10.1002/jor.20048.

[28] Rehmer A, Bishop NE, Morlock MM. Influence of assembly procedure and material combination on the strength of the taper connection at the head-neck junction of modular hip endoprostheses. Clinical Biomechanics 2012;27(1):77-83, doi:10.1016/j.clinbiomech.2011.08.002.

[29] Bergmann G, Deuretzbacher G, Heller M, Graichen F, Rohlmann A, Strauss J, Duda G. Hip contact forces and gait patterns from routine activities. Journal of Biomechanics 2001;34(7):859-71, doi:10.1016/S0021-9290(01)00040-9. 
[30] Wharton $\mathrm{MH}$, Waterhouse RB. Environmental effects in the fretting fatigue of Ti-6Al4V. Wear 1980;62(2):287-97, doi:10.1016/0043-1648(80)90174-X.

[31] Virtanen S, Milosev I, Gomez-Barrena E, Trebse R, Salo J, Konttinen YT. Special modes of corrosion under physiological and simulated physiological conditions. Acta Biomaterialia 2008;4(3):468-76, doi:10.1016/j.actbio.2007.12.003.

[32] Hoeppner DW, Chandrasekaran V. Fretting in orthopaedic implants: A review. Wear 1994;173(1-2):189-97, doi:10.1016/0043-1648(94)90272-0.

[33] Budinski KG. Tribological properties of titanium alloys. Wear 1991;151(2):203-17.

[34] Swaminathan V, Gilbert JL. Potential and frequency effects on fretting corrosion of Ti6Al4V and CoCrMo surfaces. Journal of biomedical materials research. Part A 2013;101(9):2602-12, doi:10.1002/jbm.a.34564.

[35] Archard JF. Contact and Rubbing of Flat Surfaces. Journal of Applied Physics 1953;24(8):981-88, doi:10.1063/1.1721448.

[36] Archard JF, Hirst W. The Wear of Metals under Unlubricated Conditions. Proceedings of the Royal Society A: Mathematical, Physical and Engineering Sciences 1956;236(1206):397-410, doi:10.1098/rspa.1956.0144.

[37] Frye BM, Berend KR, Morris MJ, Adams JB, Lombardi AV. Modular Femoral Tapered Revision Stems in Total Hip Arthroplasty. Joint Implant Surgery \& Research Foundation - Reconstructive Review 2013;3(4):32-37.

[38] Skendzel JG, Blaha JD, Urquhart AG. Total hip arthroplasty modular neck failure. The Journal of Arthroplasty 2011;26(2):338, doi:10.1016/j.arth.2010.03.011.

[39] Busch CA, Charles MN, Haydon CM, Bourne RB, Rorabeck CH, Macdonald SJ, McCalden RW. Fractures of distally-fixed femoral stems after revision arthroplasty. The Journal of bone and joint surgery. British volume 2005;87(10):1333-36, doi:10.1302/0301-620X.87B10.16528.

[40] Morlock MM, Schneider E, Bluhm A, Vollmer M, Bergmann G, Müller V, Honl M. Duration and frequency of every day activities in total hip patients. Journal of Biomechanics 2001;34(7):873-81, doi:10.1016/S0021-9290(01)00035-5.

[41] Wallbridge N, Dowson D. The walking activity of patients with artificial hip joints. Engineering in medicine 1982;11(2):95-96.

[42] Schmalzried TP, Szuszczewicz ES, Northfield MR, Akizuki KH, Frankel RE, Belcher G, Amstutz HC. Quantitative assessment of walking activity after total hip or knee replacement. J Bone Joint Surg Am 1998;80(1):54-59.

[43] Hussenbocus S, Kosuge D, Solomon LB, Howie DW, Oskouei RH. Head-neck taper corrosion in hip arthroplasty. BioMed Research International 2015;2015:758123, doi:10.1155/2015/758123.

[44] Morlock MM, Bunte D, Ettema H, Verheyen CC, Hamberg A, Gilbert J. Primary hip replacement stem taper fracture due to corrosion in 3 patients. Acta orthopaedica 2016;87(2):189-92, doi:10.3109/17453674.2015.1128780.

[45] Weiser MC, Chen DD. Revision for taper corrosion at the neck-body junction following total hip arthroplasty: Pearls and pitfalls. Current reviews in musculoskeletal medicine 2016;9(1):75-83, doi:10.1007/s12178-016-9322-2. 
[46] Munir S, Cross MB, Esposito C, Sokolova A, Walter WL. Corrosion in modular total hip replacements: An analysis of the head-neck and stem-sleeve taper connections. Seminars in Arthroplasty 2013;24(4):240-45, doi:10.1053/j.sart.2014.01.009.

[47] Grupp TM, Weik T, Bloemer W, Knaebel H-P. Modular titanium alloy neck adapter failures in hip replacement--failure mode analysis and influence of implant material. BMC musculoskeletal disorders 2010;11:3, doi:10.1186/1471-2474-11-3.

[48] Witt F, Bosker BH, Bishop NE, Ettema HB, Verheyen, C. C. P. M., Morlock MM. The Relation Between Titanium Taper Corrosion and Cobalt-Chromium Bearing Wear in Large-Head Metal-on-Metal Total Hip Prostheses: A Retrieval Study. The Journal of Bone \& Joint Surgery 2014;96(18):e157-e157, doi:10.2106/JBJS.M.01199.

[49] Chu Y-H, Elisa J, Duda G, Frassica F, Chao E. Stress and micromotion in the taper lock joint of a modular segmental bone replacement prosthesis. Journal of Biomechanics 2000;33:1175-79.

[50] Del Balso C, Teeter MG, Tan SC, Howard JL, Lanting BA. Trunnionosis: Does Head Size Affect Fretting and Corrosion in Total Hip Arthroplasty? The Journal of Arthroplasty 2016, doi:10.1016/j.arth.2016.03.009.

[51] Gilbert JL, Mali S, Urban RM, Silverton CD, Jacobs JJ. In vivo oxide-induced stress corrosion cracking of Ti-6Al-4V in a neck-stem modular taper: Emergent behavior in a new mechanism of in vivo corrosion. J. Biomed. Mater. Res. Part B Appl. Biomater. 2011, doi:10.1002/jbm.b.31943.

[52] Lieberman JR, Rimnac CM, Garvin KL, Klein RW, Salvati EA. An analysis of the headneck taper interface in retrieved hip prostheses. Clin. Orthop. Relat. Res. 1994(300):162-67.

[53] ASTM F67 Grade 4; Unalloyed Titanium for Surgical Implant Application, 2013.

[54] Meller MM, Toossi N, Gonzalez MH, Son MS, Lau EC, Johanson N. Surgical Risk and Costs of Care are Greater in Patients Who Are Super Obese and Undergoing THA. Clin Orthop Relat Res. 2016(474):2472-84, doi: 10.1007/s11999-016-5039-1.

[55] Traina F, Bordini B, De Fine M, Toni A. Patient weight more than body mass index influence total hip arthroplasty long term survival. Hip Int. 2011(21,6):694-9, doi: 10.5301/HIP.2011.8879.

[56] Haverkamp D, Klinkenbijl MN, Somford MP, Albers GH, van der Vis HM. Obesity in total hip arthroplasty - does it really matter? A meta-analysis. Acta Orthop. 2011(82,4):417-22, doi: 10.3109/17453674.2011.588859.

[57] Viste A, Perry KI, Taunton MJ, Hanssen AD, Abdel MP. Proximal femoral replacement in contemporary revision total hip arthroplasty for severe femoral bone loss. Bone Joint J. 2017(99-B):325-9, doi: 10.1302/0301-620X.99B3.BJJ-2016-0822.R1.

[58] Amanatullah DF, Howard JL, Siman H, Trousdale RT, Mabry TM, Berry DJ. Revision total hip arthroplasty in patients with extensive proximal femoral bone loss using a fluted tapered modular femoral component. Bone Joint J. 2015(97-B):312-7, doi: 10.1302/0301-620X.97B3.34684.

[59] Dzaja I, Lyons MC, McCalden RM, Naudie DD, Howard JL. Revision hip arthroplasty using a modular revision hip system in case of severe bone loss. J Arthroplasty. 2014 $(29,8): 1594-7$, doi: 10.1016/j.arth.2014.02.035. 
591 592

[60] Bischel OE, Böhm PM. The use of a femoral revision stem in the treatment of primary or secondary bone tumors of the proximal femur: a prospective study of 31 cases. J Bone Joint Surg Br. 2010(92,10):1435-41, doi: 10.1302/0301-620X.92B10.24024.

[61] Graham DF, Modenese L, Trewartha G, Carty CP, Constantinou M, Lloyd DG, Barrett RS. Hip joint contact loads in older adults during recovery from forward loss of balance by stepping. J Biomech. 2016(49,13):2619-24, doi: 10.1016/j.jbiomech.2016.05.033.

[62] Bergmann G, Graichen F, Rohlmann A. Hip joint contact forces during stumbling. Langenbecks Arch Surg. 2004(389,1):53-9, doi: 10.1007/s00423-003-0434-y.

[63] Timoshenko S. Strength of Materials: Part I, Elementary Theory and Problems, 3d ed. D. Van Nostrand Co., New York, 1955. 442.

[64] Australian Orthopaedic Association. National joint replacement registry. Revision hip and knee arthroplasty. Supplementary report 2017.

[65] Brehm, P.; internal document, 2015. 